responsible for the observations that the heart rate for a given level of physical activity was lower in the iron-treated than placebo-treated subjects.

The economic implications of increased work productivity with iron treatment are evident, particularly in developing countries. These results also provide strong evidence for the clinical notion that subjects with iron-deficiency anaemia are characterised by tiredness and weakness. We do not know whether this effect is related to iron deficiency or to the degree of anaemia that might be critical for a change in voluntary activity to occur as a result of iron treatment.

This study was supported by J B Williams Co, New York. We also acknowledge the co-operation of the staff in the clinical research unit (Nuffield Foundation), Kandy General Hospital, Sri Lanka, especially Miss H Perera and Mr G A Senewiratne. We are indebted to Ms A
Gardner, Ms $M$ Edgerton, $M r$ Ratwatte, and $\mathrm{Mr}$ Shadrack, staff of the Oodawella Estate, for their help in the field; and to Ms K B Hartman and Ms J D Moss for their help in the data"analysis.

\section{References}

${ }^{1}$ Basta, S S, and Churchill, A, World Bank Staff, Working Paper, No 175. Washington, DC, World Bank, 1974.

${ }^{2}$ Popkin, B M, et al, report submitted to Department of Public Works, Philippines, February, 1975.

${ }^{3}$ Viteri, F E, et al, American fournal of Clinical Nutrition, 1971, 24, 1418.

4 Glover, J, and Jacobs, A, British Medical fournal, 1972, 2, 627.

${ }^{5}$ Edgerton, V R, et al, Fournal of Nutrition, 1977, 107, 1595.

${ }^{6}$ Ohira, Y, et al, Nutrition Reports International, 1978, 18, 647.

${ }^{7}$ Ohira, Y, et al, British fournal of Haematology, 1979, 41, 365.

\title{
Pruritus ani: is anal sphincter dysfunction important in aetiology?
}

\author{
ANTHONY A EYERS, JAMES P S THOMSON
}

British Medical fournal, 1979, 2, 1549-1551

\section{Summary and conclusions}

Forty-three patients whose principal symptom was pruritus ani were studied. Twenty-eight had anal disease, while in 15 no such disease could be shown. Maximum resting pressures and transient and sustained pressures of the anal canal in response to rectal distension were measured by manometry. Although the maximum resting pressure in the patients with no disease was about the same as that in the group with disease, the pressures recorded in response to rectal distension were significantly lower.

These results show that the anal sphincter relaxes in response to rectal distension more readily in patients with no anal disease. Hence soiling may occur, which may be a factor in the genesis of pruritus ani.

\section{Introduction}

Pruritus ani is a troublesome symptom that is associated with most forms of anal disease, but in some patients with this symptom no aetiological anal disease may be found. As soiling is a frequent feature in the history of these patients, even in those without anal disease, we decided to assess the anal sphincter function by manometry ${ }^{1-3}$ in a group of patients in whom pruritus ani was the major presenting symptom.

\section{Patients and methods}

Between October 1978 and March 1979, 49 patients whose principal symptom was pruritus ani were seen at three of this hospital's six regular outpatient clinics. Six patients were excluded from the study: four refused manometry, and two had previously undergone internal sphincterotomy. Table I shows the age and sex distribution of the 43 patients studied. Six normal young male volunteers were also studied.

TABLE I-Age distribution of patients studied (mean age $44 \cdot 2$ (range 20-72) years)

\begin{tabular}{|c|c|c|c|c|c|c|c|}
\hline & Age (years): & $20-29$ & $30-39$ & $40-49$ & $50-59$ & $60-69$ & $70-79$ \\
\hline $\begin{array}{l}\text { Men } \\
\text { Women }\end{array}$ & 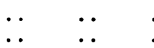 & 4 & 11 & $\begin{array}{r}10 \\
5\end{array}$ & $\begin{array}{l}7 \\
2\end{array}$ & $\begin{array}{l}2 \\
1\end{array}$ & 1 \\
\hline
\end{tabular}

\section{CLINICAL METHODS}

In taking a careful history from each patient particular note was made of whether the patient (1) frequently experienced minor degrees of soiling of his underwear with faeces at times other than when this might be explained by rubbing or scratching the area, and (2) had a generalised chronic or recurring rash. In performing an anorectal examination (comprising inspection, palpation, proctoscopy, and sigmoidoscopy) particular note was made of (1) the severity of the local changes in pruritus, graded on an arbitrary scale $(1=$ no changes, $4=$ pronounced changes); and (2) the presence or absence of any anal disease to which the pruritus might be attributed. In the group studied this included haemorrhoids, fissure in ano, anal-canal polyps, and anal skin tags. All examinations were performed by two clinicians, one of whom was always AAE.

The height and weight of each patient were measured.

\section{MYCOLOGICAL CULTURES}

Perianal skin scrapings were taken from each patient, and a record was kept of any growth of Candida albicans or filamentous fungus within six weeks after inoculation on to appropriate culture plates.

\section{ANAL-CANAL MANOMETRY}

Patients attended one to three weeks after the initial assessment for anal manometry. This procedure was performed in each case by the same clinician, who used a routine technique, and without specific reference to the records made at the first visit. 
The manometry was performed using a water-filled, round rubber balloon (external diameter $3 \mathrm{~mm}$ ) connected by fine tubing (external diameter $1.5 \mathrm{~mm}$ ) to a strain gauge, amplifier, and recorder, which produced a permanent recording on light-sensitive paper. After calibration the resting pressure in the anal canal was recorded at $1-\mathrm{cm}$ intervals from $6 \mathrm{~cm}$ to $1 \mathrm{~cm}$ from the anal verge. A soft rubber balloon on a fine tube was then passed into the rectum, with its lowermost part $6 \mathrm{~cm}$ from the anal verge. The recording balloon was repositioned in the lower anal canal between 1.0 and $2.0 \mathrm{~cm}$ from the anal verge and a continuous recording made of the anal-canal pressure while the balloon in the rectum was filled with air in $50 \mathrm{ml}$ increments to $150 \mathrm{ml}$. This volume was well tolerated by each patient and control studied. ${ }^{2-4}$ The following pressures were determined.

Maximum resting pressure (measured as $\mathrm{cm}_{2} \mathrm{O}$ ) was defined as the maximum pressure recorded at any of the standard levels in the anal canal.

Pressures after rectal distension-Figure 1 shows a tracing of the anal-canal response to rectal distension performed in the standard manner. Immediately after distension of the rectum a fall occurs in

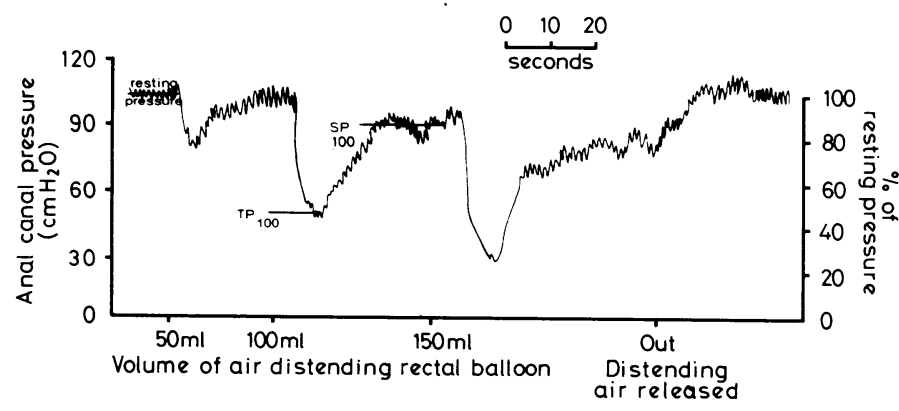

FIG 1-Tracing of anal-canal pressure in response to $50 \mathrm{ml}$ increments in volume of air used in rectal distension, showing resting pressure, transient pressure (TP), and sustained pressure (SP).

anal-canal pressure, which has two distinct phases: a transient wave of maximal relaxation followed by a sustained plateau of partial relaxation. This pattern occurs after each increment in rectal distension and is well documented. ${ }^{2} 3$ The pressure remaining in the anal canal was measured at each of the two phases to obtain the transient and sustained pressures, and the results were expressed as a percentage of the resting pressure recorded before distension. The transient and sustained pressures were calculated for each $50-\mathrm{ml}$ increment in the volume of air used in rectal distension.

\section{STATISTICAL METHODS}

In the statistical analysis the two-sample Student's $t$ test, $\chi^{2}$ test, and Mann-Whitney $\mathrm{U}$ test (using a $\mathrm{z}$ correction for large values of $\mathrm{n}$ ) were used as indicated.

\section{Results}

Anal disease: comparability of groups-Twenty-eight patients had anal disease while 15 had no such disease. There was no significant difference between these two groups in sex, age, weight, height, the incidence of soiling, presence of a rash, severity of perianal skin changes, or results of mycological cultures (table II).

Manometry studies-In three patients the recordings obtained by manometry were unsuitable for analysis owing to excessive action of the external sphincter. All were men with anal disease, and they were excluded from further consideration. The mean $( \pm S D)$ maximum resting pressures obtained in each group studied were $109 \cdot 2+26 \cdot 2$ (range 150-75) $\mathrm{cm} \mathrm{H}_{2} \mathrm{O}$ in the controls; $124 \cdot 2 \pm 24 \cdot 0(170-70) \mathrm{cm}$ $\mathrm{H}_{2} \mathrm{O}$ in the patients with anal disease; and 102.3 $\pm 35 \cdot 3(175-40) \mathrm{cm}$ $\mathrm{H}_{2} \mathrm{O}$ in the patients with no anal disease. Thus there was no significant difference between the groups. At the three volumes of air used to distend the rectum there was no significant difference in transient or sustained pressure between the controls and the patients with anal disease, but at each point the patients with no anal disease had significantly lower transient and sustained pressures than the patients with anal disease (fig 2 and table III).
TABLE II-Comparison of patients with and without anal disease with respect to clinical details, severity of changes in pruritus, and results of mycological culture

\begin{tabular}{|c|c|c|c|c|}
\hline & & $\begin{array}{c}\text { Anal } \\
\text { disease }\end{array}$ & $\begin{array}{l}\text { No anal } \\
\text { disease }\end{array}$ & $\begin{array}{c}\text { Statistical } \\
\text { analysis }\end{array}$ \\
\hline 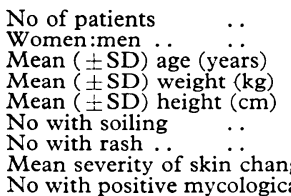 & $\begin{array}{ll}\cdots & \cdots \\
\cdots & \cdots \\
\cdots & \cdots \\
\cdots & \cdots \\
\cdots & \cdots \\
\cdots & \cdots \\
\text { ales } & \\
\text { al cultures }\end{array}$ & $\begin{array}{l}28 \\
6: 22 \\
46 \cdot 5 \pm 12 \cdot 8 \\
69 \cdot 2 \pm 10 \cdot 9 \\
169 \cdot 6 \pm 10 \cdot 3 \\
8 \\
5 \\
2 \cdot 7 \\
6\end{array}$ & $\begin{array}{l}15 \\
3: 12 \\
39 \cdot 9 \pm 8 \cdot 8 \\
74 \cdot 1 \pm 10 \cdot 9 \\
171 \cdot 9 \pm 7 \cdot 5 \\
9 \\
4 \\
2 \cdot 6 \\
3\end{array}$ & $\begin{aligned} \chi^{2} & =0.08 \\
t & =1.94 \\
t & =1.36 \\
t & =0.82 \\
\chi^{2} & =2.83 \\
\chi^{2} & =0.08 \\
\chi^{2} & =0.08\end{aligned}$ \\
\hline
\end{tabular}

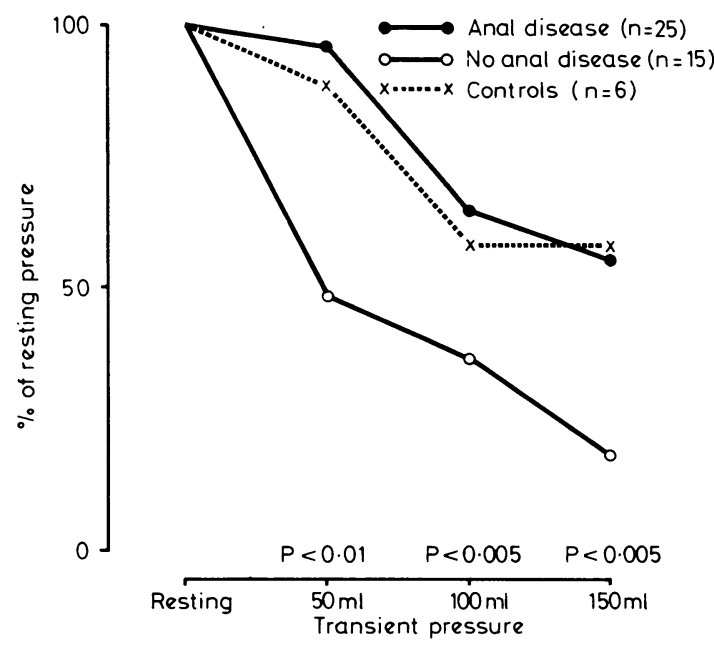

FIG 2-Median transient pressure resting and at volumes of 50,100 , and $150 \mathrm{ml}$ of air used to distend rectum in patients and controls.

TABLE III-Median sustained pressures (and ranges), expressed as percentage of resting pressure, at each incremental volume of air up to $150 \mathrm{ml}$ used to distend rectum in patients with and without anal disease and controls

\begin{tabular}{lccccc}
\hline $\begin{array}{l}\text { Volume } \\
\text { of air }\end{array}$ & & Controls & $\begin{array}{c}\text { Patients } \\
\text { with anal } \\
\text { disease }\end{array}$ & $\begin{array}{c}\text { Patients } \\
\text { without anal } \\
\text { disease }\end{array}$ & Significance* \\
\hline $50 \mathrm{ml}$. & $\ldots$ & $100(100-94)$ & $100(100-75)$ & $84(100-44)$ & $\mathrm{P}<0.01$ \\
$100 \mathrm{ml}$. & $\ldots$ & $94(100-81)$ & $85(100-22)$ & $67(100-50)$ & $\mathrm{P}<0.01$ \\
$150 \mathrm{ml} .$. &.. & $95(100-57)$ & $73(93-13)$ & $33(100-19)$ & $\mathrm{P}<0.001$ \\
\hline
\end{tabular}

*Difference between patients with and without anal disease (Mann-Whitney $U$ test).

\section{Discussion}

These consecutive patients with pruritus ani referred to a specialist centre comprised a large group with anal disease and a smaller group with no such disease. The incidence of soiling in both subgroups was considerable. In the patients with disease this may be explained by interference with anal-canal closure or the patients' ability to maintain adequate cleanliness of the area. In those with no disease the soiling is less readily explained.

We found no significant difference in the maximum resting pressure between the patients with and without anal disease. The slightly higher maximum resting pressures found in the patients with disease as compared with those without disease and the controls probably reflect that patients with haemorrhoids have higher resting pressures than normal. ${ }^{2}$ The results show that in patients with no anal disease the sphincter relaxes in response to rectal distension more readily and profoundly than in those with disease or in controls. In these patients without disease, rectal distension due to the arrival of faeces or flatus may in this way allow minute amounts of faeces to escape from the anus. Faecal soiling, however slight, is possibly a factor in 
the genesis of pruritus ani. Faeces contain bacteria whose metabolic products include endopeptidases, which can produce itching in experimental conditions. ${ }^{5}$ e

Although dysfunction of the anal sphincter itself may not be the cause of pruritus ani, it may be an important contributing factor. Further studies are required of the action of the sphincters in this condition, together with studies of the faecal and perianal skin flora. Nevertheless, the results reported here suggest an important new approach that may help to elucidate this troublesome ailment.

We wish to acknowledge the support of the St Mark's Research Foundation; the help of Sir Alan Parks and Mr M E Neill, of the research department of anorectal physiology at St Mark's Hospital and Dr Elizabeth Shaw, of the department of microbiology of the Medical College of St Bartholomew's Hospital. We also thank Mrs Mary Groves for her secretarial help.

\section{References}

${ }^{1}$ Brossey, J J, Proceedings of the Royal Society of Medicine, 1955, 48, 499.

2 Ihre, T, Scandinavian fournal of Gastroenterology, 1974, 9, suppl No 25.

${ }^{3}$ Kerremans, R, Morphological and Physiological Aspects of Anal Continence and Defaecation. Brussels, Arscia Vitgaven, 1969.

${ }^{4}$ Hancock, B D, Gut, 1976, 17, 645.

${ }^{5}$ Keele, C A, Proceedings of the Royal Society of Medicine, 1957, 50, 477.

6 Shelley, W B, and Arthur, R P, Archives of Dermatology, 1957, 76, 296.

(Accepted 3 October 1979)

\section{SHORT REPORTS}

\section{Rotaviruses and the respiratory tract}

Rotavirus infection is the commonest cause of acute non-bacterial gastroenteritis in infancy and childhood, but the method by which the virus is transmitted is not established. Several studies, however, have noted an upper respiratory prodrome or concurrent respiratory symptoms and signs in infants and young children with rotavirusinduced gastroenteritis, ${ }^{1-3}$ suggesting a possible upper respiratory infection, and this has lead to speculation that transmission may be by respiratory droplet. Two reports have shown that gastroenteritis caused by rotaviruses is associated with otitis media ${ }^{28}$; one described it in patients with rotavirus-induced gastroenteritis but not in gastroenteritis caused by other agents. We therefore tried to detect rotavirus in the upper respiratory tract during natural rotavirus infection in neonates and young children admitted to $\mathrm{St}$ Thomas's Hospital during the months December 1978 to April 1979.

\section{Patients, methods, and results}

Stool specimens were obtained and nasopharyngeal secretions (NPS) were collected by suction catheter within seven days (mean of 3.5 and 3.8 days respectively) of onset of gastrointestinal symptoms from 24 neonates and young children ( $<3$ years) and from 23 age-matched controls who were in the same ward but not suffering from gastroenteritis. The cathete contents were flushed out with 5-10 ml viral transport medium, mechanically shaken for one hour at $37^{\circ} \mathrm{C}$, and an aliquot removed for routine viral isolation in tube cultures of human embryo lung fibroblasts, $\mathrm{HeLa}$, and cynomolgus monkey kidney cells. Nasopharyngeal cells were separated by centrifugation, washed three times in phosphate-buffered saline (PBS), fixed in acetone, and stored at $-70^{\circ} \mathrm{C}$ for subsequent detection of rotavirus by immunofluorescence (IF) employing a swine anti-human rotavirus and a rabbit antiswine FITC conjugate. The supernatant was ultracentrifuged at $100000 \mathrm{~g}$ for one hour, the pellet resuspended in $0.5 \mathrm{ml} \mathrm{PBS}$, and examined by negative-staining electronmicroscopy (EM) using 3\% phosphotungstic acid pH 6.5, solid phase immune EM (SPIEM), and enzyme-linked immunosorbent assay (ELISA). ${ }^{4}$ SPIEM was by a modification of the method described by Derrick. ${ }^{5}$ Carbon-coated collodion grids were floated on a drop of $1: 100$ dilution of a high titre goat antihuman rotavirus antiserum (provided by Dr R H Yolken, NIH, Bethesda)! in 0.1 M phosphate buffer $\mathrm{pH} 7.0$ containing $0.1 \%$ bacitracin in a humified chamber for 15 minutes. Grids were then washed with 25 drops of buffer, drained, and floated on a drop of the test sample for 15 minutes. After a second buffer washing the grids were washed with five drops of $3 \%$ phosphotungstate $\mathrm{pH}$ 6.5, drained, dried, and examined in a Philips EM 201C at $100 \mathrm{kv}$.

Thirteen of the 24 patients with gastroenteritis excreted rotavirus in their stools, 10 having upper respiratory features including coryza, cough, and otitis media. But, despite obtaining NPS from two patients before the onset of their gastrointestinal symptoms, no patients had rotavirus detectable in NPS by EM, SPIEM, or ELISA. Nasopharyngeal cells from all patients were negative for rotavirus by IF. No viruses were isolated from NPS in cell cultures or seen on direct EM. Rotavirus was not detected in NPS or stools from asymptomatic control patients.

\section{Comment}

Our preliminary investigations suggest that rotaviruses do not replicate in the nasopharynx: we used highly sensitive tests to detect their presence. We calculated that by direct $\mathrm{EM}>5 \times 10^{4}$ rotavirus particles $/ \mathrm{ml}$ can be detected. SPIEM and ELISA are more sensitive and can detect $\geqslant 1 \times 10^{4}$ particles $/ \mathrm{ml}$. Failure to detect rotavirus in respiratory secretions was unlikely to be because virus was no longer being excreted via the respiratory tract by the time gastroenteritis developed, since we obtained NPS from two children one and five days respectively before the onset of gastroenteritis. Why so many patients with rotavirus-induced gastroenteritis have upper respiratory tract features remains to be explained.

We thank Sara Palmer and W Stone for cell culture work.

1 British Medical fournal, 1977, 2, 784.

${ }^{2}$ Lewis, H M, et al, Archives of Disease in Childhood, 1979, 54, 339.

${ }^{3}$ Goldwater, P N, fournal of Infection, 1979 (in press).

${ }^{4}$ Yolken, R H, et al, Lancet, 1977, 2, 263.

5 Derrick, K S, Virology, 1973, 56, 652.

(Accepted 3 October 1979)

\section{Department of Virology, St Thomas's Hospital and Medical School,} London SE1 7EH

PAUL N GOLDWATER, MB, senior registrar

IAN L CHRYSTIE, BSC, lecturer

J E BANATVALA, MD, FRCPATH, professor of clinical virology

\section{Bitter lemon purpura}

Severe thrombocytopenia due to drug-induced platelet antibodies is relatively unusual, although drugs that can produce this effect are widely encountered. Even the minute amount of quinine present in tonic water $(80 \mu \mathrm{g} / \mathrm{ml})$ is sufficient to cause severe thrombocytopenia ("cocktail purpura"). ${ }^{1}$ We describe its occurrence in a sensitised individual after drinking a single glass of bitter lemon containing $20 \mu \mathrm{g} / \mathrm{ml} /$ quinine. There was no indication that the brand contained quinine.

\section{Case report}

A 16-year-old schoolgirl awoke one morning feeling weak and shivery. Later in the day purpuric haemorrhages appeared on her arms, face, and legs. Six days later she had a severe epistaxis and on admission to hospital was found to have extensive purpura and petechiae. The spleen was impalpable and general physical examination was otherwise normal. Six weeks earlier she had been prescribed quinine sulphate tablets for nocturnal leg cramps, although she admitted to taking tablets irregularly. Investigations showed haemoglobin $11.3 \mathrm{~g} / \mathrm{dl}$; white cell count $5.5 \times 10^{9} / 1\left(5500 / \mathrm{mm}^{3}\right)$; platelet count $15 \times 10^{9} / 1\left(15000 / \mathrm{mm}^{3}\right)$; prothrombin ratio 1.2 ; partial thromplastin time kinase $39 \mathrm{~s}$; fibrinogen $2.8 \mathrm{~g} / \mathrm{l}$. No underlying cause for the thrombocytopenia was found. The marrow aspirate contained normal numbers of megakaryocytes. The diagnosis rested between idiopathic thrombocytopenic purpura and a drug-induced thrombocytopenia. The patient was therefore given a platelet transfusion on admission and started 